\title{
The prevalence of hypertension among Malaysian adults and its associated risk factors: data from Malaysian Community Salt Study (MyCoSS)
}

Nor Azian Mohd Zaki i*, Rashidah Ambak², Fatimah Othman², Norazizah Ibrahim Wong², Cheong Siew Man², Mohamad Faizul Azham Morad², Feng J. He ${ }^{3}$, Graham MacGregor ${ }^{3}$, Lalitha Palaniveloo ${ }^{2}$ and Azli Baharudin²

\begin{abstract}
Background: Hypertension is one of the most common risk factors for cardiovascular disease and leading cause of mortality globally. The aims of this study were to assess the prevalence of hypertension and its associated risk factors among Malaysian population using data from the Malaysian Community Salt Study (MyCoSS).

Methods: This study was a cross-sectional study using multi-stage stratified sampling method. Data collection was carried out via face-to-face interview at the respondent's home from October 2017 until March 2018. A total of 1047 respondents aged 18 years and above completed the questionnaires and blood pressure measurement. A person who reported diagnosis of hypertension by a physician and had systolic blood pressure $\geq 140 \mathrm{mmHg}$ and/or diastolic blood pressure $\geq 90 \mathrm{mmHg}$ on three readings was categorised as hypertensive. Risk factors of hypertension were analysed using multiple logistic regression.

Results: The prevalence of hypertension in the present study was 49.39\% (95\% Cl 44.27-54.51). There was no statistically significant difference in gender. Age, household income, BMI, and diabetes were significantly associated with hypertension. Hypertension found had inverse association with the level of education. Age was the strongest predictor of hypertension (35-44 years old; $\mathrm{OR}=2.39,95 \% \mathrm{Cl}=1.39-4.09,45-54$ years old; $\mathrm{OR}=5.50,95 \% \mathrm{Cl}=3.23-9.38$, 55-64 years old $\mathrm{OR}=13.56,95 \% \mathrm{Cl}=7.77-23.64$ and 65 years old and above; $\mathrm{OR}=25.28,95 \% \mathrm{Cl}=13.33-48.66)$. Those who had higher BMI more likely to be hypertensive as compared to respondents with normal weight (overweight, $\mathrm{OR}=1.84 ; 95 \% \mathrm{Cl}=1.18-2.86$; obese, $\mathrm{OR}=4.29 \% \mathrm{Cl}=2.56-7.29$ ).

Conclusion: The findings showed that hypertension is prevalent among adults in Malaysia. Those with older age, higher BMI, and diabetes are more likely to have hypertension. Efforts regarding lifestyle modification and education could be important in hypertension management and prevention.
\end{abstract}

Keywords: Malaysian community salt study (MyCoSS), Hypertension, Blood pressure, Cardiovascular disease

\footnotetext{
*Correspondence: norazianmz@moh.gov.my

'Sarawak General Hospital, Ministry of Health, Kuching, Sarawak, Malaysia

Full list of author information is available at the end of the article
} 


\section{Background}

Cardiovascular disease (CVD) is the largest cause of non-communicable disease (NCD) deaths with an estimated 17.6 million people died worldwide in 2012 [1]. Hypertension is well established as an important risk factor for CVD and was diagnosed as systolic blood pressure $(\mathrm{SBP}) \geq 140 \mathrm{mmHg}$ and/or diastolic blood pressure $(\mathrm{DBP}) \geq 90 \mathrm{mmHg}[2,3]$. Besides hypertension, CVD risk factors also include abdominal obesity, dyslipidemia, and insulin resistance also known as "metabolic syndrome" [3].

Hypertension has become more prevalent over the past decades worldwide including in developing countries due to various factors, including economic development and population ageing [4]. Data from the National Health and Nutrition Examination Survey (NHANES) found that rates of hypertension among US adults increased from $23.9 \%$ in $1988-1994$ to $29.0 \%$ in $2007-$ 2008 [5]. Prevalence of hypertension was about 27\% in Southeast Asian region [6]. In 2010, it is estimated that 325 million Chinese adult aged 18 years or older were diagnosed with hypertension [7]. In Thailand, one out of four Thais had hypertension and almost half of them were not aware that they had high blood pressure [8]. The national prevalence of hypertension among Malaysian adults was $30.3 \%$ with rates increasing with age as reported by National Health and Morbidity Survey (NHMS) in 2015 [9].

Many epidemiological studies have established the risk factors for hypertension. These included age, gender, weight, body mass index (BMI), waist circumference (WC), sedentary lifestyle, smoking and alcohol intake [10-12]. Others have implicated lipid disorders, diabetes, salt intake and family history of high blood pressure [13]. More recently, attention has been drawn to excess intake of salt and its major role in the pathogenesis of higher blood pressure [14]. Although local studies on lifestyle risk factors and hypertension were available, the relationship between hypertension and dietary sodium intake are limited. Therefore, this study aims to determine the prevalence and associated risk factors of hypertension including dietary sodium intake among Malaysian adult population using data from the Malaysian Community Salt Study (MyCoSS).

\section{Methodology}

\section{Study design}

MyCoSS is a cross-sectional study which used a multistage stratified sample design to obtain a nationally representative sample. One eligible adult aged 18 to 59 years old was selected from each household using Kish table to participate in the survey. A total of 1047 respondents were giving consents to take part in this study. Face-to-face interviewed at respondents' homes were done using mobile devices during the data collection period between October 2017 and March 2018.

Information on sociodemographic characteristics including gender, age, education level, marital status and household income were collected. Lifestyle behaviours, such as current smoking status and physical activity status, were also assessed. To assess physical activity, a validated Short-International Physical Activity Questionnaire (Short-IPAQ) in Malay version was used [15]. Respondents were asked whether they currently smoked cigarettes to assess current smoking status. Diabetes was diagnosed as random blood sugar $\geq 11.1 \mathrm{mmol} / \mathrm{l}$ or selfreport of previous diagnosis of diabetes by doctors [16]. Assessment of dietary sodium intake using food frequency questionnaire (FFQ) from a previous study comprises 104 food items [17].

\section{Blood pressure measurements}

Blood pressure measurements were measured with a digital blood pressure monitor (Omron HBP-1300). Measurement of blood pressure was taken three times in a stable condition with 1- to 2-min interval between each measurement. The average of last two measurement of systolic blood pressure (SBP) and diastolic blood pressure (DBP) were used to determine high blood pressure. The Malaysia Guideline on the Management of Hypertension, 4th Edition, 2013, was used to defined hypertension [18]. A person who reported diagnosis of hypertension previously by a physician and had SBP $\geq 140 \mathrm{mmHg}$ and/or DBP $\geq 90 \mathrm{mmHg}$ was diagnosed as hypertensive. Respondents within normal or prehypertensive range were categorised into the normal group (normotensive).

\section{Anthropometry variables}

Body weight and height was measured using digital weighing scale (TANITA HD-319) and SECA 213 portable stadiometer with an accuracy of $0.1 \mathrm{~kg} / 0.1 \mathrm{~cm}$, respectively. SECA measuring tape (SECA, Germany) used to measured waist circumference. All measurements were done using validated and calibrated instruments and following standardised protocols. Body mass index (BMI) was computed as weight to the square of height $\left(\mathrm{kg} / \mathrm{m}^{2}\right)$ and categorised according to WHO 1998 guidelines [19].

\section{Statistical analysis}

All categorical variables were presented as frequency and percentages while continuous variable was presented as mean with $95 \%$ confidence interval (CI). Differences in proportions between categorical variables were analysed using chi-square. Univariate and multiple logistic regression was performed to explore the effects of age, gender, marital status, education level, household 
income, smoking, physical activity status, diabetes, BMI, and waist circumference as the risk factors for hypertension. The adjusted odds ratios were presented with 95\% confidence interval (CI) with $p$ value $<0.05$ was accepted as statistically significant. Data analyses were done using SPSS version 21.0.

\section{Results}

A total of 1047 respondents with mean age of 48.80 years (95\% CI 47.03-50.61). The characteristics related with normotensive and hypertensive state among respondents are shown in Table 1 . The prevalence of hypertension in present study was $49.39 \%$ (95\% CI 44.27-54.51) with no significant difference in gender. Prevalence of hypertension was higher among married group (79.96\%; 95\% CI 74.70-84.36) and those in low household income group (50.83\%; 95\% CI 43.92-57.70). Higher prevalence of hypertension was shown among those with primary education level (33.77\%; 95\% CI 27.40-40.78) and secondary education level (48.02\%; 95\% CI 43.16-52.92) as compared to those with tertiary education (18.20\%; 95\% CI 12.37-25.96). Individuals

Table 1 Baseline characteristic of respondents with normotensive and hypertension

\begin{tabular}{|c|c|c|c|c|c|c|}
\hline \multirow[t]{2}{*}{ Characteristic } & & \multicolumn{2}{|c|}{ Normotensive } & \multicolumn{2}{|c|}{ Hypertensive } & \multirow[t]{2}{*}{$P$ value } \\
\hline & & $\%$ & $95 \% \mathrm{Cl}$ & $\%$ & $95 \% \mathrm{Cl}$ & \\
\hline Overall & & 50.60 & $45.48-55.71$ & 49.39 & $44.27-54.51$ & \\
\hline \multirow[t]{2}{*}{ Sex } & Male & 50.42 & $44.74-56.10$ & 49.95 & $43.77-56.13$ & 1.00 \\
\hline & Female & 49.57 & $43.89-55.25$ & 50.04 & $43.86-56.22$ & \\
\hline Age, years (mean, 95\% Cl) & & 40.76 & $38.92-42.60$ & 57.09 & $55.62-58.56$ & $<0.001$ \\
\hline \multirow[t]{5}{*}{ Age group } & $<34$ & 38.62 & $32.83-44.76$ & 4.88 & $3.03-7.75$ & $<0.001$ \\
\hline & $35-44$ & 23.41 & $18.49-29.16$ & 10.84 & $7.56-15.30$ & \\
\hline & $45-54$ & 20.40 & $16.04-25.59$ & 20.20 & $16.31-24.73$ & \\
\hline & $55-64$ & 12.62 & $8.61-18.12$ & 34.29 & $28.96-40.04$ & \\
\hline & $>65$ & 4.93 & $2.99-8.02$ & 29.78 & $24.28-35.93$ & \\
\hline \multirow[t]{3}{*}{ Academic level } & None/primary & 14.86 & $10.71-20.24$ & 33.77 & $27.40-40.78$ & $<0.001$ \\
\hline & Secondary & 54.58 & $48.57-60.46$ & 48.02 & $43.16-52.92$ & \\
\hline & Tertiary & 30.55 & $24.61-37.21$ & 18.20 & $12.37-25.96$ & \\
\hline \multirow[t]{3}{*}{ Household income } & $<$ RM1999 & 35.04 & $27.68-43.20$ & 50.83 & $43.92-57.70$ & $<0.001$ \\
\hline & RM2000-RM3999 & 30.83 & $24.78-37.63$ & 28.97 & $23.13-35.61$ & \\
\hline & $>$ RM4000 & 34.11 & $26.72-42.36$ & 20.18 & $14.01-28.19$ & \\
\hline \multirow[t]{2}{*}{ Marital status } & Single /widowed & 28.81 & $24.07-34.06$ & 20.03 & $15.63-25.29$ & 0.052 \\
\hline & Married & 71.18 & $65.93-75.92$ & 79.96 & $74.70-84.36$ & \\
\hline BMI $\left(\mathrm{kg} / \mathrm{m}^{2}\right)$, (mean, 95\% Cl) & & 25.68 & $25.08-26.28$ & 27.65 & $26.99-28.30$ & $<0.001$ \\
\hline \multirow[t]{3}{*}{$\mathrm{BMI}\left(\mathrm{kg} / \mathrm{m}^{2}\right)$} & $<25$ & 46.06 & $40.18-52.06$ & 31.63 & $26.18-37.64$ & $<0.001$ \\
\hline & $25-30$ & 36.93 & $32.08-42.06$ & 38.34 & $32.14-44.92$ & \\
\hline & $\geq 30$ & 16.99 & $13.25-21.53$ & 30.01 & $24.39-36.43$ & \\
\hline WC, cm (mean, 95\% Cl) & & 86.63 & $85.20-88.06$ & 93.88 & $92.43-95.32$ & $<0.001$ \\
\hline \multicolumn{7}{|l|}{$\mathrm{WC}, \mathrm{cm}$} \\
\hline Men <90, Women <80 & No & 41.82 & $36.72-47.09$ & 23.20 & $18.15-29.17$ & $<0.001$ \\
\hline Men $\geq 90$, Women $\geq 80$ & Yes & 58.17 & $52.90-63.26$ & 76.79 & $70.82-81.84$ & \\
\hline \multirow[t]{2}{*}{ Smoking status } & No & 74.50 & $69.43-70.99$ & 82.53 & $77.00-86.95$ & $<0.001$ \\
\hline & Yes & 25.49 & $21.00-30.56$ & 17.46 & $13.04-22.99$ & \\
\hline \multirow[t]{2}{*}{ Physical activity } & Inactive & 42.93 & $35.61-50.57$ & 40.53 & $34.33-47.04$ & 0.448 \\
\hline & Active & 57.06 & $49.42-38.59$ & 59.46 & $52.95-65.66$ & \\
\hline \multirow[t]{2}{*}{ Diabetes } & No & 90.81 & $85.42-94.34$ & 64.44 & $58.36-70.09$ & $<0.001$ \\
\hline & Yes & 9.18 & $5.65-14.57$ & 35.55 & $29.90-41.63$ & \\
\hline \multirow[t]{2}{*}{ Sodium intake (mg/day) } & $<2000$ & 39.56 & $33.49-45.93$ & 52.47 & $47.35-57.54$ & $<0.001$ \\
\hline & $\geq 2000$ & 60.43 & $54.03-66.50$ & 47.52 & $42.45-52.64$ & \\
\hline
\end{tabular}


with hypertension had significantly greater mean BMI $\left(27.65 \mathrm{~kg} / \mathrm{m}^{2}, 95 \%\right.$ CI $26.99-28.30$, vs $25.68 \mathrm{~kg} / \mathrm{m}^{2}, 95 \%$ CI 25.08-26.28) and waist circumference index (93.88 cm, 95\% CI 92.43-95.32, vs $86.63 \mathrm{~cm}, 95 \%$ CI 85.20 88.06) than those with normal blood pressure.

Table 2 shows various risk factors associated with hypertension. Univariate analysis showed that age, academic level, household income, marital status, BMI, waist circumference, current smoking, diabetes and total sodium intake were independently associated with increased odds for hypertension. Hypertension shown had negatively associated with the level of education. After controlling for other covariates, age was the strongest predictor of hypertension (35-44 years old; $\mathrm{OR}=2.39$, 95\% $\mathrm{CI}=1.39-4.09,45-54$ years old; $\mathrm{OR}=5.50,95 \% \mathrm{CI}=$
$3.23-9.38$, 55-64 years old $\mathrm{OR}=13.56,95 \% \mathrm{CI}=7.77-$ 23.64 and 65 years old and above; $\mathrm{OR}=25.28,95 \% \mathrm{CI}=$ 13.33-48.66). Overweight or obese respondents were more likely to be hypertensive compared to normal weight (overweight, $\mathrm{OR}=1.84 ; 95 \% \mathrm{CI}=1.18-2.86$; obese, $\mathrm{OR}=4.29 ; 95 \% \mathrm{CI}=2.56-7.29)$.

\section{Discussion}

The prevalence of hypertension in our study was $49.4 \%$, which is higher than the nationally representative data set of 19,936 Malaysian adults in 2015 (35.3\%) [20]. However, the result was comparable with Abdul-Razak et al. who found $47.9 \%$ of Malaysian adults aged more than 30 years were diagnosed with hypertension [21]. The rising of hypertension and other non-communicable

Table 2 Factors associated with hypertension from univariate and multivariate logistic regression model

\begin{tabular}{|c|c|c|c|c|c|}
\hline \multirow[t]{2}{*}{ Characteristic } & & \multicolumn{2}{|l|}{ Univariate analysis } & \multicolumn{2}{|c|}{ Multivariate analysis } \\
\hline & & OR $(95 \% \mathrm{Cl})$ & $p$ value & OR $(95 \% \mathrm{Cl})$ & $p$ value \\
\hline \multirow[t]{2}{*}{ Sex } & Male & 1.00 (reference) & 0.986 & & \\
\hline & Female & $1.02(0.78-1.28)$ & & & \\
\hline \multirow[t]{5}{*}{ Age group } & $>34$ & 1.00 (reference) & & 1.00 (reference) & \\
\hline & $35-44$ & $3.34(2.04-5.45)$ & $<0.001$ & $2.39(1.39-4.09)$ & 0.002 \\
\hline & $45-54$ & $7.35(4.62-11.67)$ & $<0.001$ & $5.50(3.23-9.38)$ & $<0.001$ \\
\hline & $55-64$ & $19.35(12.01-31.17)$ & $<0.001$ & $13.56(7.77-23.64)$ & $<0.001$ \\
\hline & $>65$ & $32.04(18.58-55.25$ & $<0.001$ & $25.38(13.13-48.66)$ & $<0.001$ \\
\hline \multirow[t]{3}{*}{ Academic level } & None/primary & 1.00 (reference) & & 1.00 (reference) & \\
\hline & Secondary & $0.37(0.28-0.51)$ & $<0.001$ & $0.69(0.46-1.02)$ & 0.064 \\
\hline & Tertiary & $0.19(0.14-0.29)$ & $<0.001$ & $0.58(0.34-0.98)$ & 0.042 \\
\hline \multirow[t]{3}{*}{ Household income } & $<$ RM1999 & 1.00 (reference) & & 1.00 (reference) & \\
\hline & RM2000-RM3999 & $0.65(0.49-0.87)$ & 0.003 & $1.54(1.04-2.28)$ & 0.031 \\
\hline & $>\mathrm{RM} 4000$ & $0.43(0.31-0.59)$ & $<0.001$ & $0.74(0.46-1.16)$ & 0.735 \\
\hline \multirow[t]{2}{*}{ Marital status } & Single/widowed & 1.00 (reference) & & 1.00 (reference) & \\
\hline & Married & $1.32(1.01-1.74)$ & 0.045 & $1.12(0.47-1.61)$ & 0.550 \\
\hline \multirow[t]{3}{*}{$\mathrm{BMI}\left(\mathrm{kg} / \mathrm{m}^{2}\right)$} & $<25$ & 1.00 (reference) & & 1.00 (reference) & \\
\hline & $25-30$ & $1.85(1.39-2.46)$ & $<0.001$ & $1.84(1.18-2.86)$ & 0.007 \\
\hline & $\geq 30$ & $3.34(2.40-4.64)$ & $<0.001$ & $4.29(2.55-7.29)$ & $<0.001$ \\
\hline \multicolumn{6}{|l|}{$\mathrm{WC}, \mathrm{cm}$} \\
\hline Men $<90$, women $<80$ & No & 1.00 (reference) & & 1.00 (reference) & \\
\hline Men $\geq 90$, women $\geq 80$ & Yes & $2.53(1.94-3.30)$ & $<0.001$ & $1.16(0.74-1.79)$ & 0.518 \\
\hline \multirow[t]{2}{*}{ Smoking status } & No & 1.00 (reference) & 0.003 & 1.00 (reference) & 0.82 \\
\hline & Yes & $0.63(0.46-0.86)$ & & $0.96(0.64-1.42)$ & \\
\hline \multirow[t]{2}{*}{ Physical activity } & Inactive & 1.00 (reference) & 0.438 & & \\
\hline & Active & $0.91(0.71-1.16)$ & & & \\
\hline \multirow[t]{2}{*}{ Diabetes } & No & 1.00 (reference) & $<0.001$ & 1.00 (reference) & $<0.001$ \\
\hline & Yes & $5.71(3.89-8.39)$ & & $2.48(1.59-3.87)$ & \\
\hline \multirow[t]{2}{*}{ Sodium intake (mg/d) } & $<2000$ & 1.00 (reference) & $<0.001$ & 1.00 (reference) & 0.686 \\
\hline & $\geq 2000$ & $0.53(0.42-0.68)$ & & $0.94(0.68-1.29)$ & \\
\hline
\end{tabular}

*Significance at $p$ value $<0.05$ 
disease (NCD) was correlated with modernisation and an increasing economy status with most Malaysians adopted sedentary lifestyles and high consumption of high calorie, salty and fatty food [22].

This study found no significant difference in prevalence of hypertension by gender. This finding was in contrast with findings from other studies that showed a higher prevalence of hypertension was detected in men than in women [21]. Limited sample size may have influenced to the differing results in rate of hypertension among men and women. Consistent with other studies, hypertension prevalence was lowest among those with higher income status and higher academic level among the Malaysian population, similar to other countries in the region $[23,24]$.

Multivariate analysis showed that age, higher academic level, moderate household income, BMI and diabetes were significantly associated with hypertension. This study found that the prevalence of hypertension increased with age in both men and women. Similar results were seen among adults in India and Taiwan [11, 25]. Academic level was shown as a protective factor and the result was similar with a study in China [13]. Better knowledge on healthy lifestyle and being well informed about blood pressure management may contribute to lower risk of hypertension among those with higher education level [26].

Our findings confirmed the finding from previous studies that BMI and diabetes were associated with high risk of hypertension [7, 27]. A study conducted by Papathanasiou et al. suggest greater BMI was significantly and directly related with increased resting blood pressure in both gender [28]. However, waist circumference did not show an association with hypertension in this study. Feng et al. suggested that waist circumference is strongly independently associated with diabetes because the measurement reflects an accumulation of intra-abdominal fat that could lead to insulin resistance. Meanwhile, BMI is associated with hypertension due to increase in body weight (BMI) which may increase body fluid volume, peripheral resistance and cardiac output [25].

Excess consumption of dietary sodium has a main role in the pathogenesis of elevated blood pressure. A study by Zhang et al. showed that high sodium intake was positively related with systolic blood pressure [26]. Our result indicated that in multivariable analysis, no significantly different between sodium intake and hypertension. The results may be due to limitations of crosssectional study design and the dietary data that was collected using food frequency questionnaire. Compared with 24-h sodium excretion, estimation participants' usual sodium intake from food frequency questionnaire in this study may under or overestimate actual intake. Other possible reason was that respondents may already be aware about risk of high salt diet with hypertension. Study by Abdul-Razak et al. found that awareness of hypertension among Malaysian adult more than 30 years of age was $53.2 \%$ [21].

There are several strengths in our study: first, the random selection of the respondents, sample size, and high participation rate, and second, examination of the relationship between BP and anthropometry, lifestyle risk factors, and dietary sodium intake added the strength of this study. The main limitation in this study was that the sampling framework is not the total population representative, and therefore, caution is needed in extrapolating the information. The limitation of sampling size may have overestimated the prevalence of hypertension as compared with national prevalence. Nevertheless, associated risk factors of hypertension indicated in this study were in line with other studies except for gender.

\section{Conclusion}

Current finding revealed that hypertension is prevalent among adult in Malaysia and it found that age, BMI, those with middle household income and diabetes were predictors of hypertension. These results further underline the need for routine blood pressure check-up to identify subjects with high-risk of hypertension. Strategies to strengthen the monitoring of modifiable risk factors including optimal weight control should be advocate for better hypertension control in Malaysia.

\section{Abbreviations}

MyCoSS: Malaysian Community Salt Study; NHMS: National Health and Morbidity Survey; CVD: Cardiovascular disease; NCD: Non-communicable disease; BMI: Body mass index; SBP: Systolic blood pressure; DBP: Diastolic blood pressure; SD: Standard deviation; Cl: Confidence interval

\section{Acknowledgements}

The authors would like to thank the Director General of Health Malaysia for permission to publish this paper. Appreciation goes to the Department of Statistics, Malaysia, in the sampling process. Acknowledgement also goes to the Ministry of Health Malaysia, namely Nutrition Division, Non-

Communicable Disease Section, State Health Departments, Liaison Officers and scouts in the preparation and during the data collection. Our sincere appreciation also goes to all data collectors and participants.

\section{About this supplement \\ This article has been published as part of Journal of Health, Population and Nutrition Volume 40 Supplement 1, 2021: Malaysian Community Salt Survey 2017-2018 (MyCoSS). The full contents of the supplement are available online at https://jhpn.biomedcentral.com/articles/supplements/volume-40- supplement-1.}

\section{Authors' contributions}

RA, FO, CSM, MFAM, FJH, GMG and AB conceived for the concept and project development. RA and FO helped supervise the project's progress. NAMZ, FO, LP and NIW analysed the data and wrote the draft manuscript. All authors provided critical feedback and helped shape the research, analysis and approved the final manuscript.

\section{Funding}

Publication costs are funded by the Newton-Ungku Omar Fund: UK Malaysia Bilateral Health Research Collaboration for Non-Communicable Diseases with the grant number of MR/P012590/1 (joint funding from the 
Academy of Sciences Malaysia, Malaysian Industry-Government Group for High Technology, and the Medical Research Council, UK). The funders had no role in the study design, data collection, data analysis, data interpretation or writing of the article.

\section{Availability of data and materials}

The dataset of this article belongs to the MyCoSS project. At present, the data are not publicly available but can be obtained from the authors upon reasonable request and with the permission from the Director General of Health, Malaysia.

\section{Declarations}

\section{Ethics approval and consent to participate}

Ethical approvals of the study were obtained from the Medical Research Ethics Committee (MREC), Ministry of Health Malaysia (NMRR-17-423-34969) and Queen Mary (University of London) Research Ethics Committee (MR/ P012590/1) prior to conducting the study. Informed written consent was obtained from all respondents before the start of study.

\section{Consent for publication}

Not applicable.

\section{Competing interests}

The authors declare that they have no competing interests.

\section{Author details}

${ }^{1}$ Sarawak General Hospital, Ministry of Health, Kuching, Sarawak, Malaysia. ${ }^{2}$ Institute for Public Health, National Institutes of Health, Ministry of Health Malaysia, Shah Alam, Selangor, Malaysia. ${ }^{3}$ Wolfson Institute of Preventive Medicine, Barts and The London School of Medicine \& Dentistry, Queen Mary University of London, London, UK.

Published: 31 May 2021

\section{References}

1. McAloon CJ, Boylan LM, Hamborg T, Stallard N, Osman F, Lim PB, et al. The changing face of cardiovascular disease 2000-2012: an analysis of the world health organisation global health estimates data. Int J Cardiol. 2016;224: 256-64

2. World Health Organisation. A global brief on hypertension: silent killer, global public health crisis. Geneva: WHO Press WHO; 2013.

3. National Institute for Health $(\mathrm{NIH})$. The seventh report of the joint National Committee on prevention, detection, evaluation, and treatment of high blood pressure (JNC7): National Institute for Health (NIH); 2004.

4. Bromfield S, Muntner P. High blood pressure: the leading global burden of disease risk factor and the need for worldwide prevention programs. Curr Hypertens Rep. 2013;15(3):134-6.

5. Egan BM, Zhao Y, Axon RN. US trends in prevalence, awareness, treatment and control of hypertension, 1988-2008. JAMA. 2010;303(20):2043-50.

6. Neupane D, McLachlan CS, Sharma R, Gyawali B, Khanal V, Mishra SR, et al. Prevalence of hypertension in member countries of south Asian Association for Regional Cooperation (SAARC): systematic review and meta-analysis. Med. 2014;93(13):1-10

7. Wang J, Zhang L, Wang F, Liu L, Wang H. Prevalence, awareness, treatment, and control of hypertension in China: results from a national survey. Am J Hypertens. 2014;27(11):1355-61.

8. Sakboonyarat B, Mungthin M. Prevalence and associated factors of uncontrolled hypertension among Thai patients with hypertension: a nationwide cross-sectional survey. Rev Épidémiol Santé Publique. 2018;66: S310-1.

9. Institute For Public Health. National Health and Morbidity Survey. Vol II: Non communicable disease, risk factors and other health. In: Problem; 2015.

10. Park J, Lee J-S, Kim J. Relationship between dietary sodium, potassium, and calcium, anthropometric indexes, and blood pressure in young and middle aged Korean adults. Nutr Res Pract. 2010;4(2):155-62.

11. SIngh RB, Fedacko J, Pella D, Macejova Z, Ghosh S, De AK, et al. Prevalence and risk factors for prehypertension and hypertension in five Indian cities. Acta Cardiol. 2011;66(1):29-37.

12. Li G, Wang H, Wang K, Wang W, Dong F, Qian Y, et al. Prevalence, awareness, treatment, control and risk factors related to hypertension among urban adults in Inner Mongolia 2014: differences between Mongolian and Han populations. BMC Public Health. 2016;16(1):294

13. Sun $Z$, Zheng $L$, Wei $Y$, Li J, Zhang $X$, Zhang $X$, et al. Prevalence and risk factors of the rural adult people prehypertension status in Liaoning Province of China. Circ J. 2007;71(4):550-3.

14. Appel LJ, Frohlich ED, Hall JE, Pearson TA, Sacco RL, Seals DR, et al. The importance of population-wide sodium reduction as a means to prevent cardiovascular disease and stroke: a call to action from the American Heart Association. Circulation. 2011;123(10):1138-43.

15. Teh C, Lim K, Chan Y, Lim K, Azahadi O, Akmar AH, et al. The prevalence of physical activity and its associated factors among Malaysian adults: findings from the National Health and morbidity survey 2011. Public Health. 2014; 128(5):416-23.

16. Ministry of Health. Clinical practice guidelines: Management of Tye 2 diabetes mellitus. 5th edition. Putrajaya: Ministry of Health Malaysia; 2015.

17. Institute for Public Health. Determination of dietary sodium intake among the Ministry of Health staff (MySalt 2015): National Institutes of Health, Ministry of Health Malaysia; 2015.

18. Ministry of Health. Clinical practice guidelines: Management of Hypertension 5th edition. Putrajaya: Ministry of Health Malaysia; 2018.

19. World Health Organization. Obesity: Preve nting and managing the global epidemic. Report of a WHO consultation on obesity. Geneva: World Health Organization; 1998.

20. Ab Majid NL, Omar MA, Khoo YY, Mahadir Naidu B, Ling Miaw Yn J, Rodzlan Hasani WS, et al. Prevalence, awareness, treatment and control of hypertension in the Malaysian population: findings from the National Health and morbidity survey 2006-2015. J H Hypertens. 2018;32(8-9):617-24.

21. Abdul-Razak S, Daher AM, Ramli AS, Ariffin F, Mazapuspavina MY, Ambigga KS, et al. Prevalence, awareness, treatment, control and socio demographic determinants of hypertension in Malaysian adults. BMC Public Health. 2016; 16:351.

22. Khor G-L. Food availability and the rising obesity prevalence in Malaysia leJSM. 2012;6(suppl 1):S61-8.

23. Naing C, Yeoh PN, Wai VN, Win NN, Kuan LP, Aung K. Hypertension in Malaysia: an analysis of trends from the national surveys 1996 to 2011. Med. 2016;95(2):e2417.

24. Do HT, Geleijnse JM, Le MB, Kok FJ, Feskens EJ. National prevalence and associated risk factors of hypertension and prehypertension among Vietnamese adults. Am J Hypertens. 2015;28(1):89-97.

25. Lin SJ, Lee KT, Lin KC, Cheng KH, Tsai WC, Sheu SH, et al. Prevalence of prehypertension and associated risk factors in a rural Taiwanese adult population. Int J Cardiol. 2010;144(2):269-73.

26. Li $X$, Ning N, Hao Y, Sun H, Gao L, Jiao M, et al. Health literacy in rural areas of China: hypertension knowledge survey. Int J Environ Res Public Health. 2013;10(3):1125.

27. Meng XJ, Dong GH, Wang D, Liu MM, Liu YQ, Zhao Y, et al. Epidemiology of prehypertension and associated risk factors in urban adults from 33 communities in China--the CHPSNE study. Circ J. 2012;76(4):900-6.

28. Papathanasiou G, Zerva E, Zacharis I, Papandreou M, Papageorgiou E, Tzima

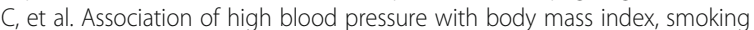
and physical activity in healthy young adults. Open Cardiovasc Med J. 2015; 9:5-17.

\section{Publisher's Note}

Springer Nature remains neutral with regard to jurisdictional claims in published maps and institutional affiliations.

Ready to submit your research? Choose BMC and benefit from:

- fast, convenient online submission

- thorough peer review by experienced researchers in your field

- rapid publication on acceptance

- support for research data, including large and complex data types

- gold Open Access which fosters wider collaboration and increased citations

- maximum visibility for your research: over $100 \mathrm{M}$ website views per year

At BMC, research is always in progress.

Learn more biomedcentral.com/submission 